\title{
In Silico Taste, Cytochrome and Toxicity Prediction Study of Major Chamomile Constituents
}

\author{
Kafa Khalaf Hammud \\ Ministry of Science and Technology - Iraq
}

Article information

Article history:

Received: October, 30, 2021

Accepted: November, 12, 2021

Available online: December, 14, 2021

Keywords:

Chamomile,

Cytochrome enzymes,

Toxicity,

In Silico

*Corresponding Author:

Kafa Khalaf Hammud

kafaakhalaf@gmail.com

DOI:

https://doi.org/10.53523/ijoirVol8I3ID106

\begin{abstract}
Chamomile is an ancient herb used for various medications. It contains many bioactive constituents such as volatile oils, terpenoids, flavonoids, lactones, acid esters, glycosides and others. By reviewing many references, a confliction appeared of using Chamomile preparations to treat primary teeth eruption symptoms as a therapy administered by pediatric dentist or pediatrician. In this study, thirteen bioactive constituents ( $\alpha$-bisabolol (B), chamazulene (C), umbelliferone (U), apigenin (A), apigetrin (AT), apiin (AI), luteolin (L), quercetin (Q), quercimertrin $(\mathrm{QT})$, rutin $(\mathrm{R}), \alpha$-cadinene $(\mathrm{CD}), \alpha$-farnesene $(\mathrm{F})$, and matricarin $(\mathrm{M})$ were subject to computational predication through various online websites to predicate their taste, activity towards several CYP450 enzymes and their action as Hepatotoxic, carcinogenic, immunotoxic, mutagenic, and cytotoxic compounds. Our calculations revealed several points such as high value of taste predication indicated that Chamomile constituents under study were with sour taste, did not classify as individual fatal compound Class (GHS) 1 or 2, 44.87\% of them showed inhibition character toward specific cytochrome P450 enzyme while $43.59 \%$ were non- inhibition character, more than $(0.5)$ probability predication of various cytochrome P450 enzymes gave a positive activity that may affect liver functions. Also, hepatotoxicity, carcinogenicity, immunotoxicity, mutagenicity, and cytotoxicity predictions were more than (0.5), unsaturated Chamomile constituent (Farnesene, F) had highest immune - and mutagenic properties whilst the disaccharide flavonoid (Rutin, R) had the highest Carcinoimmunogenic response. According to the above notes, our conclusion is to use minimum concentration of Chamomile preparation for less period of time and lowest repeating intake that ensure effective treatment of teething symptoms under supervision of pediatricians with minimum side effect.
\end{abstract}

\section{Introduction}

Many herbs around the world are known to be used for medicinal applications, Chamomile is one of them. It classifies as Asteraceae or Compositae family member being in German and Roman varieties. Most uses of its extracts are for healing promotion or drinking as a tea. It interplays as curative, inhibitive, and preventive preparations because it contains many bioactive constituents such as volatile oils, terpenoids, flavonoids, lactones, 
acid esters, glycosides and others. Chamomile toxic side effect is limited because of its slow initiation to reach maximum activity. Extraction conditions determine quality and quantity of these bioactives [1].

According to reference [2] in Contra-indication, warning section of German or Roman Chamomile" In view of the documented allergic reactions and cross sensitivities, Chamomile should be avoided by individual with a known hypersensitivity to any members of the Asteraceae/ Compositae family. In addition, Chamomile may precipitate an allergic reaction exacerbate existing symptoms in susceptible individuals (e.g. asthmatics). The use of Chamomile preparations for teething babies is not recommended". This medical notice is very important and it opens a gate to research question and answer. But it is conflicting with one of British Medical Journals (BMJ) founding [3] after studying 62 infants with teething symptoms which its results indicated "a significant effect of Chamomile water extract on relieving teething symptoms, especially pain which caused irritability, compared with placebo ( $\mathrm{p}<0.0001) "$. Also, steam distillation oil of Chamomile flower is administered to children at teething stage beside other medicinal activities was mentioned in [4]. Another reference [5] stated that "Chamomile products are also used to soothe inflammation of the mouth and gums, and for infant teething". Also, the same meaning was written by Sharafzadeh and Alizadeh [6]

To find an scientific answer to this confliction "Is (or not) recommended at this baby stage?", in Silico study was taken to predicate taste, activity of cytochromes, and toxicity of $\alpha$-bisabolol, chamazulene, umbelliferone, apigenin, apigetrin, apiin, luteolin, quercetin, quercimertrin, rutin, $\alpha$-cadinene, $\alpha$-farnesene, and matricarin in Chamomile. This in Silico study was done by applying various online predication websites.

\section{Experimental Procedure}

Predication characters according to its online website. In this study, predication characters were taste (bitter, sweet, and sour) by http://virtualtaste.charite.de (Table (1)), activity of various cytochrome enzymes by http://insilicocyp.charite.de/SuperCYPsPred/ (Table (2)) and https://preadmet.bmdrc.kr/adme/ (Table (3)) websites, and toxicity by https://tox-new.charite.de/protox_II/ (Table (4)) website.

\section{Bioactives in online predication methods}

They were $\alpha$-Bisabolol(B), chamazulene (C), umbelliferone (U), apigenin (A), apigetrin (PT), apiin (AI), luteolin $(\mathrm{L})$, quercetin $(\mathrm{Q})$, quercimertrin $(\mathrm{QT})$, rutin $(\mathrm{R}), \alpha$-cadinene $(\mathrm{CD}), \alpha$-farnesene $(\mathrm{F})$, and matricarin $(\mathrm{M})$ that chosen as mainly representative bioactive compounds in Chamomile (Figure (1)).

\section{Results and Discussion}

Chamomile is characterized as low -growing apple scent expressing its Greek name Chamos (ground) and melos (apple) [7]. It presents a pleasant taste with various medicinal effects including anti- inflammatory, anticancer (skin, breast, ovarian, or prostate), antioxidant, antiphlogisitis, treatment of wound, acute viral nasopharyngitis (known as common cold), infant colic disorder, haemorrhoids, mucositis, osteoporosis, vaginitis, improving cardiac health, managing diabetes, sleep, sedation, anxiety, seizure, eczema, digestive disorders, diminishing hyperglycaemia - related oxidative stress, and others $[1,8,9]$.

Numerical Taste predication (Table (1), Figure (2)) confirmed sour probability of the tested constituents ranged (o.537-1) for bitter, (0.546-0.989) for sweet, and (0.834-1) for sour character. These predication results were of individuals not as all in one mixture.

Table (1). Taste character of some Chamomile constituents according to http://virtualtaste.charite.de website.

\begin{tabular}{|l|c|c|c|c|c|c|c|c|c|c|c|c|c|}
\hline Taste & B & C & U & A & AT & AI & \multicolumn{1}{|c}{ L } & Q & QT & R & CD & F & M \\
\hline Bitter & 0.583 & 0.738 & 0.625 & 0.998 & 0.544 & 0.65 & 1.0 & 1.0 & 0.537 & 0.746 & 0.852 & 0.687 & 0.842 \\
\hline Sweet & 0.685 & 0.831 & 0.581 & 0.628 & 0.546 & 0.732 & 0.989 & 0.989 & 0.684 & 0.979 & 0.873 & 0.629 & 0.684 \\
\hline Sour & 0.974 & 0.834 & 0.998 & 1.0 & 0.996 & 0.999 & 1.0 & 1.0 & 1.0 & 0.999 & 0.960 & 0.903 & 0.952 \\
\hline
\end{tabular}


Table (2). Activity of Cytochrome enzymes towards bioactive Chamomile constituents according to http://insilico-cyp.charite.de/SuperCYPsPred/ website.

\begin{tabular}{|c|c|c|c|c|c|c|c|c|c|c|c|c|c|c|}
\hline \multicolumn{2}{|c|}{ Enzyme } & B & $\mathrm{C}$ & $\mathrm{U}$ & A & AT & AI & $\mathrm{L}$ & Q & QT & $\mathrm{R}$ & CD & $\mathrm{F}$ & $\mathrm{M}$ \\
\hline \multirow{5}{*}{$\begin{array}{l}\tilde{U} \\
\mathbb{Z} \\
\sum\end{array}$} & CYP1A2 & 0.955 & 0.675 & 0.657 & 1.0 & 0.959 & 0.957 & 1.0 & 1.0 & 1.0 & 0.983 & 0.85 & 0.944 & 0.914 \\
\hline & CYP2C19 & 0.81 & 0.679 & 0.813 & 0.998 & 0.963 & 0.859 & 0.779 & 0.779 & 0.996 & 0.993 & 0.769 & 0.944 & 0.907 \\
\hline & CYP2C9 & 0.553 & 0.606 & 0.609 & 0.812 & 0.862 & 0.676 & 0.993 & 0.993 & 0.928 & 0.901 & 0.662 & 0.717 & 0.693 \\
\hline & CYP2D6 & 0.876 & 0.757 & 0.914 & 0.891 & 0.947 & 0.781 & 0.85 & 0.85 & 0.965 & 0.928 & 0.688 & 0.777 & 0.806 \\
\hline & CYP3A4 & 0.897 & 0.915 & 0.953 & 1.0 & 1.0 & 0.968 & 0.794 & 0.794 & 1.0 & 0.999 & 0.951 & 1.0 & 0.888 \\
\hline \multirow{5}{*}{$\begin{array}{l}\text { 駕 } \\
\text { "ू }\end{array}$} & CYP1A2 & 0.918 & 0.546 & 0.519 & 1.0 & 0.821 & 0.824 & 0.986 & 0.961 & 0.833 & 0.729 & 0.79 & 0.897 & 0.942 \\
\hline & CYP2C19 & 0.909 & 0.793 & 0.898 & 0.672 & 0.873 & 0.85 & 0.886 & 0.9 & 0.933 & 0.971 & 0.864 & 0.909 & 0.953 \\
\hline & CYP2C9 & 0.791 & 0.5 & 0.733 & 0.63 & 0.938 & 0.883 & 0.678 & 1.0 & 0.869 & 0.928 & 0.817 & 0.622 & 0.904 \\
\hline & CYP2D6 & 0.722 & 0.534 & 0.717 & 0.868 & 0.903 & 0.842 & 0.868 & 0.533 & 0.846 & 0.854 & 0.601 & 0.757 & 0.85 \\
\hline & CYP3A4 & 0.859 & 0.72 & 0.847 & 0.894 & 0.95 & 0.828 & 0.579 & 0.751 & 0.895 & 0.824 & 0.918 & 0.902 & 0.842 \\
\hline
\end{tabular}

Table (3). Cytochrome enzymes towards bioactive Chamomile constituents according to https://preadmet.bmdrc.kr/adme/ website. (Inh.: inhibitor, Sub.: Substrate).

\begin{tabular}{|c|c|c|c|c|c|c|}
\hline Enzyme & $\begin{array}{c}\text { CYP2C19 } \\
\text { inhibition }\end{array}$ & $\begin{array}{c}\text { CYP2C9 } \\
\text { inhibition }\end{array}$ & $\begin{array}{c}\text { CYP2D6 } \\
\text { inhibition }\end{array}$ & $\begin{array}{c}\text { CYP2D6 } \\
\text { substrate }\end{array}$ & $\begin{array}{c}\text { CYP3A4 } \\
\text { inhibition }\end{array}$ & $\begin{array}{c}\text { CYP3A4 } \\
\text { substrate }\end{array}$ \\
\hline B & Inh. & Inh. & Non & Non & Non & Sub. \\
\hline C & Inh. & Inh. & Non & Non & Inh. & Sub. \\
\hline U & Inh. & Inh. & Non & Non & Non & Non \\
\hline A & Inh. & Inh. & Non & Non & Non & Non \\
\hline AT & Inh. & Inh. & Non & Non & Inh. & Weakly \\
\hline AI & Inh. & Inh. & Non & Non & Inh. & Weakly \\
\hline L & Inh. & Inh. & Non & Non & Inh. & Non \\
\hline Q & Inh. & Inh. & Non & Non & Inh. & Non \\
\hline QT & Inh. & Inh. & Non & Non & Inh. & Weakly \\
\hline R & Inh. & Inh. & Non & Non & Inh. & Weakly \\
\hline CD & Inh. & Inh. & Non & Non & Non & Sub. \\
\hline F & Inh. & Inh. & Non & Non & Inh. & Sub. \\
\hline M & Inh. & Inh. & Non & Non & Inh. & Sub. \\
\hline
\end{tabular}

Table (4). Various toxicity characters of bioactives in Chamomile according to https://toxnew.charite.de/protox II/ website. (Class: Predicated toxicity class; LD 50 , Predicated LD $50, \mathrm{mg} / \mathrm{Kg}$; Hepat,

Hepatotoxicity; Carcino, Carcinogenicity; Immuno., Immunotoxicity; Mutag., Mutagenicity; Cyto., Cytotoxicity).

\begin{tabular}{|c|c|c|c|c|c|c|c|c|c|c|c|c|c|}
\hline Property & $\mathrm{B}$ & $\mathrm{C}$ & $\mathrm{U}$ & $\mathrm{A}$ & $\mathrm{AT}$ & $\mathrm{AI}$ & $\mathrm{L}$ & $\mathrm{Q}$ & $\mathrm{QT}$ & $\mathrm{R}$ & $\mathrm{CD}$ & $\mathrm{F}$ & $\mathrm{M}$ \\
\hline Class & 4 & 4 & 6 & 5 & 5 & 5 & 5 & 3 & 5 & 5 & 5 & 5 & 3 \\
\hline LD50 & 1016 & 1220 & 10000 & 2500 & 5000 & 5000 & 3919 & 159 & 5000 & 5000 & 4400 & 3650 & 125 \\
\hline Hepat. & 0.81 & 0.83 & 0.68 & 0.68 & 0.82 & 0.85 & 0.69 & 0.69 & 0.82 & 0.79 & 0.83 & 0.79 & 0.63 \\
\hline Carcino. & 0.70 & 0.60 & 0.64 & 0.62 & 0.86 & 0.81 & 0.68 & 0.68 & 0.85 & 0.88 & 0.80 & 0.73 & 0.53 \\
\hline Immuno. & 0.86 & 0.99 & 0.97 & 0.99 & 0.93 & 0.90 & 0.97 & 0.87 & 0.58 & 0.99 & 0.68 & 0.99 & 0.64 \\
\hline Mutag. & 0.75 & 0.71 & 0.83 & 0.57 & 0.59 & 0.63 & 0.51 & 0.51 & 0.76 & 0.90 & 0.60 & 0.98 & 0.70 \\
\hline Cyto. & 0.89 & 0.75 & 0.68 & 0.87 & 0.69 & 0.70 & 0.99 & 0.99 & 0.69 & 0.68 & 0.76 & 0.81 & 0.80 \\
\hline
\end{tabular}




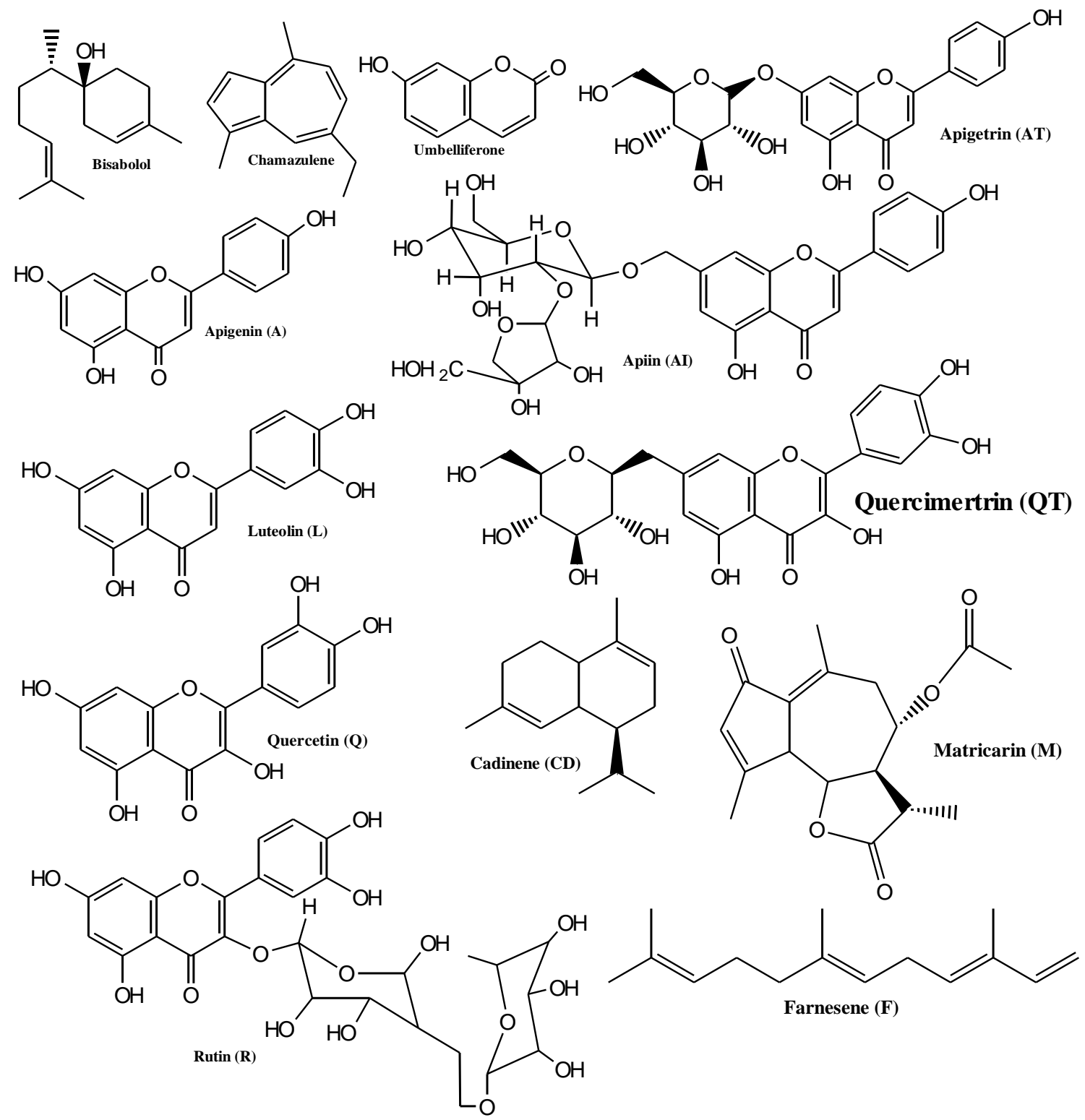

Figure (1). Bioactive constituents in Chamomile under study. 


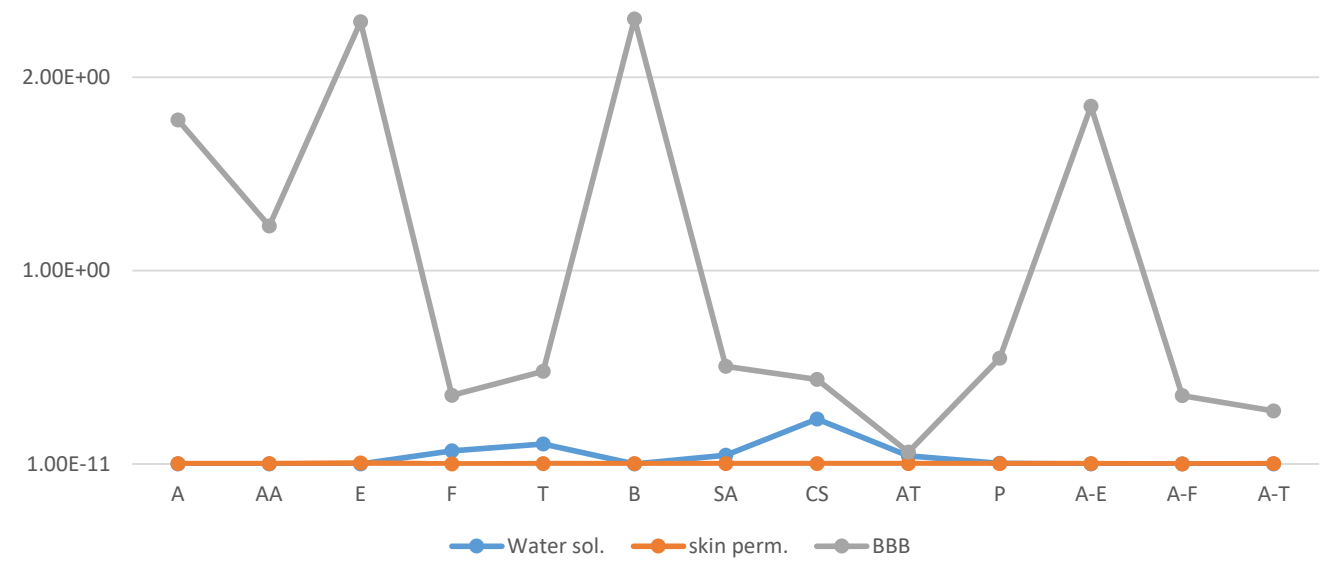

Figure (2). Taste character of Chamomile constituents under test.

Cytochrome P450 family is a superfamily of terminal oxidase enzymes composed of protein with heme group as cofactor found in all living kingdoms. Its coded enzymes based electron transfer (oxidation -reduction) chain like CYP1A2, CYP2C9, CYP2C19, and others that induction, inhibition, and competition properties specify for example drug interaction. So, CYP1A2 (Cytochrome P450 1A2) is member of this oxidase system as monooxygenase to metabolize xenobiotic, drugs, endogenous materials in body and synthesize lipids, cholesterol, steroids. Also, CYP2C19 is another monooxygenase (epoxygenase) works as liver enzyme protein in catalysis of xenobiotic metabolism $[10,11,12]$.

Cytochrome activity with tested constituents was studied with two online website http://insilicocyp.charite.de/SuperCYPsPred/ (Table (2)) and https://preadmet.bmdrc.kr/adme/ (Table (3)). According to Table (2), the results were calculated by two methodologies: Molecular Access System MACCS ("166 bit-long structural key descriptor in which each bit is associated with a specific structural pattern") and Molecular fingerprint (Morgan). The maximum difference between both methods was 0.326. Cytochrome response varied between all tested constituents but in general showed highest inhibition value with CYP3A4 (Table 2, Figures (3 \& 4)). Also, both MACCS and Morgan fingerprint showed approximately same sequence.

The other website that predicate cytochrome inhibition did not show numerical data and did not compatible in cytochrome types that been calculated (Table (3)). Figure (5) represents Table (3) results by replace inhibitor predication with 2 , weakly with 1 , non- inhibitor with 0 and substrate with 3 .

Both Table (3) and Figure (5) showed that CYP2C19 and CYP2C9 can be inhibited by all constituents under test. Additionally, CYP2D6 (Substrate and Inhibition) were with non- character for all tested compounds while CYP3A4 had been inhibited by all except $\mathrm{B}, \mathrm{U}, \mathrm{A}$, and $\mathrm{CD}$ while substrate predication of the same cytochrome were with active action by B, C, CD, F, and M. Weakly inhibition response of CYP3A4 was predicated in AI, AT, QT, and R whilst U, A, L, Q showed substrate behaviour of the same protein enzyme. 


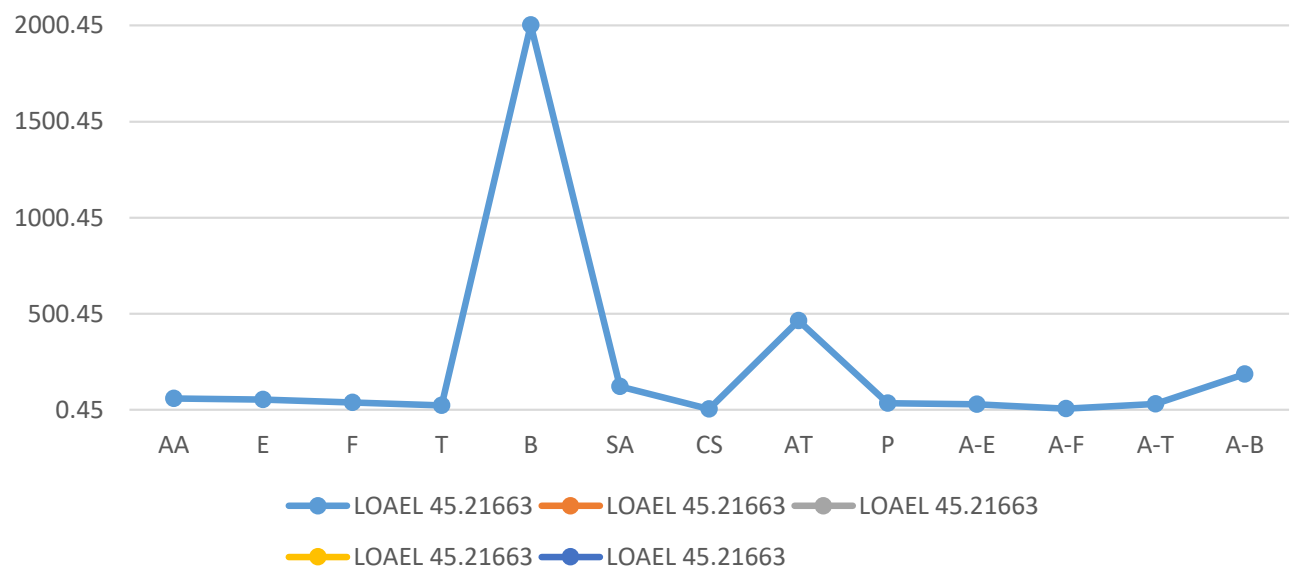

Figure (3). Cytochrome activity predication according to MACCS method.

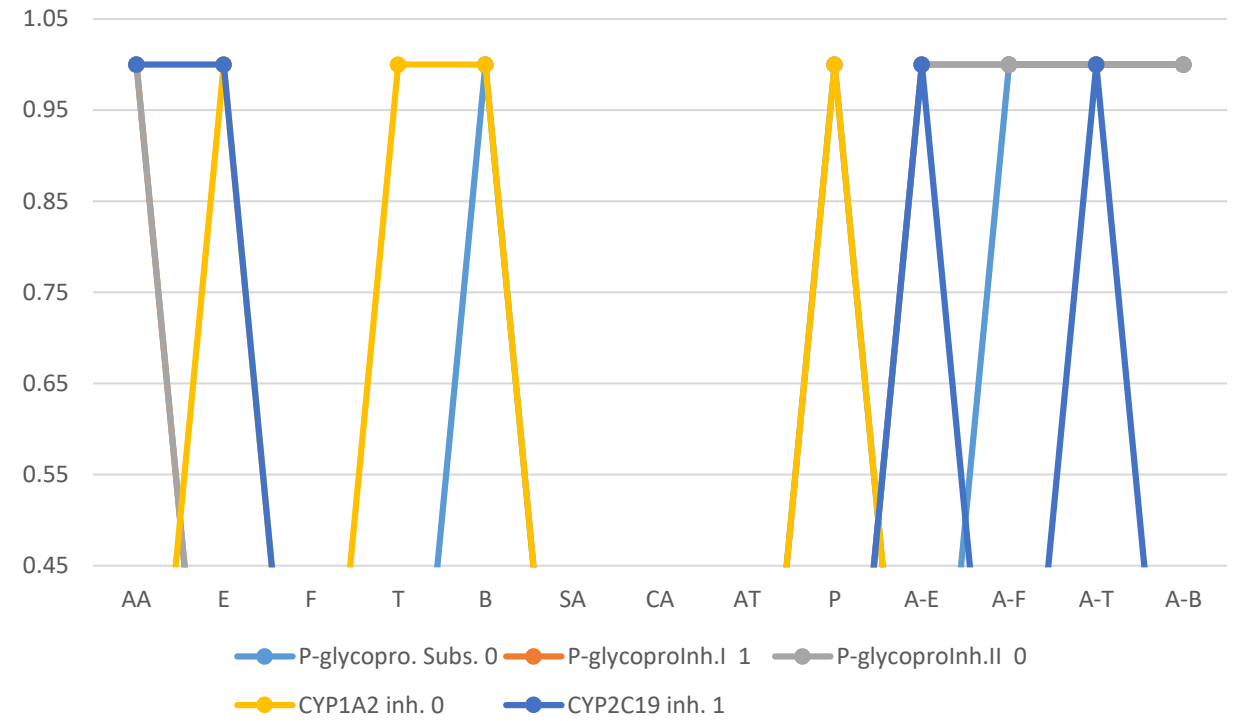

Figure (4). Cytochrome activity predication according to Morgan method.

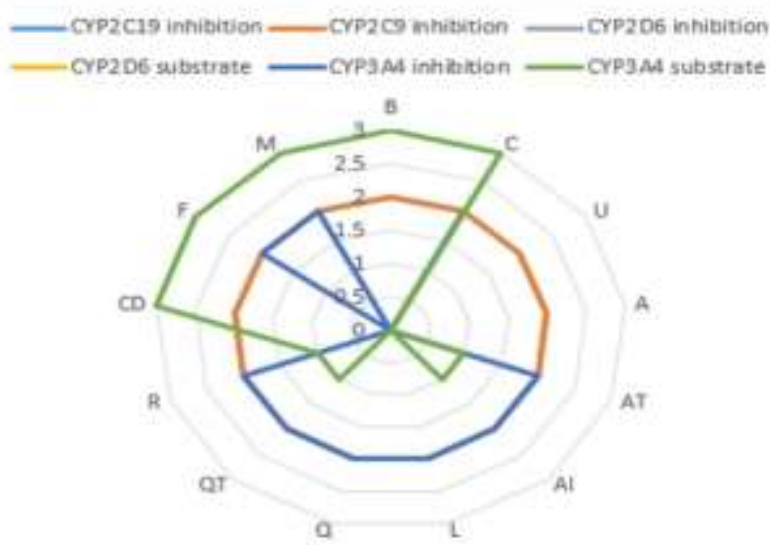

Figure (5). Representative results of Cytochrome inhibition by numbers instead of words (Inh. (2), weakly with 1, non- inhibitor with 0 and substrate with 3 ). 
Toxicity characters of bioactives in Chamomile were predicated by https://tox-new.charite.de/protox_II/ website and they toxicity class, Predicated $\mathrm{LD}_{50}, \mathrm{mg} / \mathrm{Kg}$, Hepatotoxicity, Carcinogenicity, Immunotoxicity, Mutagenicity, and Cytotoxicity (Table (4), Figure (6)). Globally Harmonized System (GHS) categorizes toxicity classes to Class: 1, fatal if swallowed with $\mathrm{LD}_{50}=5 \mathrm{mg} / \mathrm{Kg}$ or less, Class 2-fatal if swallowed (LD 50 not more than $50 \mathrm{mg} / \mathrm{Kg}$ ), Class 3-toxic if swallowed (LD 50 not more $300 \mathrm{mg} / \mathrm{Kg}$ ), Class 4- harmful if swallowed (LD 50 not more $2000 \mathrm{mg} / \mathrm{Kg}$ ), Class 5- may be harmful if swallowed (LD ${ }_{50}$ less than $5000 \mathrm{mg} / \mathrm{Kg}$ ), and Class 6- nontoxic (LD $\mathrm{L}_{50}$ more than 5000 $\mathrm{mg} / \mathrm{Kg})$.

It is a good notice that Chamomile constituents under predication (Table (4)) are not presented in Class 1 or 2 (the fatal category). The other very good sign in this Table (4) is most of these compounds may be harmful if swallowed. Class 4 had be characterized in B and C while Class 3 to Q and M. Also, U has Class 6 the safer class. From Table (4) and Figure (6), other toxicity predictors were ranged as below:

- Hepatotoxicity: $0.63(\mathrm{M})-0.85(\mathrm{AI})$.

- Carcinogenicity: $0.53(\mathrm{M})-0.88(\mathrm{R})$.

- Immunotoxicity: $0.58(\mathrm{QT})-0.99(\mathrm{C}, \mathrm{A}, \mathrm{R}, \mathrm{F})$.

- Mutagenicity: $0.51(\mathrm{~L}, \mathrm{Q})-0.98(\mathrm{~F})$.

- Cytotoxicity: $0.68(\mathrm{U}, \mathrm{R})-0.99(\mathrm{~L}, \mathrm{Q})$.

Hepatotoxicity sign caused by chemical is important in human health and drug industry and this acute liver damage sign is resulting by increasing level of specific enzyme [13, 14]. M showed the lowest acute liver damage probability while AI was the highest with 0.85 Table (4) and Figure (6). The reason behind this increase of hepatotoxicity in AI is the presence of furanosyl and glucosyl moieties in the structure of this natural flavonoid (apigenin diglycosidyl flavone) resulting more oxygen atoms that increased interaction with liver active molecules compared to $\mathrm{M}$.

When chemical inducing tumor after long time exposure and an accumulation in the target organ, this chemical identify as carcinogen and studying this sign requires in - life rat, mice, and then human testing of adsorption and metabolism $[15,16,17]$. Carcinogenic probability of $\gamma$ - butyl lactone $M$ was 0.53 as the least value compared to 0.88 of the citrus disaccharide flavonoid $\mathrm{R}$ that as the highest potential hazard (Table (4) and Figure (6)).

Immunotoxicity character of any chemical is endpoint study of in Vitro, in Vivo and / or computational models and represents the correlation between this chemical and food and cellular actions $[18,19]$. Risk probability of immune system with $\mathrm{C}$ (bicyclic unsaturated hydrocarbon with aromatic character), A (flavonoid), R (flavonoid), or F (tetraene) was the highest compared with the lowest QT (flavonoid) as shown in Table (4) and Figure (6).

Exposure of environmental species to hazard causing heritable change of DNA is Mutagenicity. This term of securing nucleotide sequence can be screened by in Vivo and computational methods to ensure quality of chemical upon living organisms [17, 18, 21, 22, 23]. Cytogenetic character of the semi-identical flavonoids L and Q was 0.51 while $\alpha$-sesquiterpene isomer $(F)$ showed the highest mutagenic predication response (0.98) (Table (4) and Figure (6)).

In vitro biocompatibility of a primary cell with chemical is a reflection of its function after this biological interaction $[24,25]$. Contrary to mutagenicity predication, the toxicity caused by the action of L and Q on living cell was 0.99 as the highest cytotoxicity compared to $\mathrm{U}$ and $\mathrm{R}$ with 0.68 in spite that Chamomile constituents (L, Q, U, and R) are flavonoids (Table (4) and Figure (6)).

It can be noticed from calculation that the unsaturated Chamomile constituent $(\mathrm{F})$ had highest immune - and mutagenic properties. In addition, the disaccharide flavonoid $(\mathrm{R})$ had the highest Carcino- immunogenic response. 


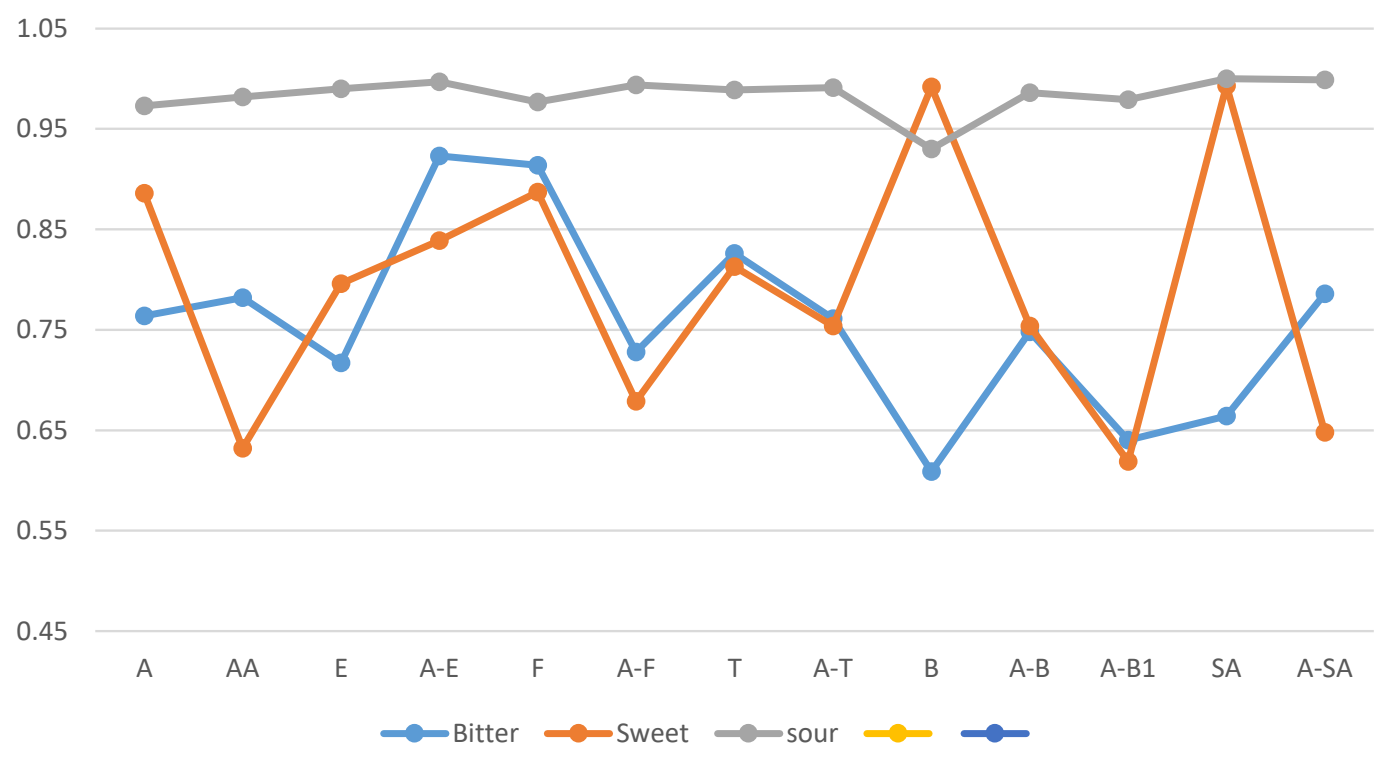

Figure (6). Toxicity predication of Chamomile constituents under test.

By back to the confliction between a notice in a scientific reference concerned of herbal medicine [2] and other published articles [3-6] that in general confirmed using Chamomile preparations to treat primary teeth eruption symptoms as a therapy administered by pediatric dentist or pediatrician followed by antipyretic prescription [26], our calculations revealed several points:

$>$ High value of taste predication indicated that Chamomile constituents under study were with sour taste.

$>$ The studied compounds did not classify as individual fatal compound Class (GHS) 1 or 2.

$>44.87 \%$ of them showed inhibition character toward specific cytochrome P450 enzyme while $43.59 \%$ were non- inhibition character.

$>$ More than (0.5) probability predication of various cytochrome P450 enzymes gave a positive activity.

$>$ Hepatotoxicity, carcinogenicity, immunotoxicity, mutagenicity, and cytotoxicity prediction probabilities were more than $(0.5)$.

$>$ Unsaturated Chamomile constituent (Farnesene, F) had highest immune - and mutagenic properties.

The disaccharide flavonoid (Rutin, R) had the highest Carcino- immunogenic response.

\section{Conclusions}

Thirteen bioactive Chamomile constituents were studied with different online website to predicate their taste, activity towards several CYP450 enzymes and their action as Hepatotoxic, carcinogenic, immunotoxic, mutagenic, and cytotoxic compounds. The computational models in these online website showed that these 13 compounds were not fatal as GHS Classification. They had a noticeable inhibition activity against various CYP450 enzymes that may affect liver functions. In general, probable Hepatotoxicity, carcinogenicity, immunotoxicity, mutagenicity, and cytotoxicity of them appeared especially Farnesene as the highest immun -mutagenic properties and Rutin as the highest Carcino- immunogenic response. According to the above notes, our conclusion is to use minimum concentration of Chamomile preparation for less period of time and lowest repeating intake that ensure effective treatment of teething symptoms under supervision of pediatricians with minimum side effect.

\section{References}

[1] A. Abbas, M. Seddik, A. Gahory, S. Salaheldin, and W. Soliman. "Differences in the Aroma Profile of Chamomile (Matricaria chamomilla L.) after different drying conditions", Sustainability, vol. 13, no. 9, pp. 5083, 2021.

[2] J. Barnes, L. Anderson, and J. Phillipson. "Herbal Medicines”' $3^{\text {rd }}$ Ed., Pharmaceutical Press, UK, 2007.

[3] S. Ebrahimi and S. Ashkani. "A comparison of Chamomile and placebo in relieving teething symptoms". Arch. Dis. Childhood 93, pw308, 2008. 
[4] P. Ravindran, M. Divakaran, and G. Pillai. "Other herbs and spices: achiote to Szechuan pepper" Chapter 27 in Handbook of Herbs and Spices, $2^{\text {nd }}$ Ed., Vol. 2, Woodhead Publishing Series in Food Science, Technology and Nutrition, K. Peter (Ed.), ScienceDirect, USA, 2012.

[5] S. Edwards, I. Rocha, E. Williamson, and M. Heinrich. "Phytopharmacy: An Evidence - Based Guide to Herbal Medical Products, Chamomile, German Matricaria Chamomilla L" Chapter 24, John Wiley \& Sons, Ltd., UK, 2015.

[6] S. Sharafzadeh and O. Alizadeh "German and Roman Chamomile", Journal Applied Pharmaceutical Science, vol. 1, no.10, pp.1-5, 2011.

[7] N. Sotiropoulou, S. Megremi, and P. Tarantilis, "Evaluation of antioxidant activity, toxicity, and phenolic profile of aqueous extracts of Chamomile (Matricaria chamomilla L.) and Sage (Salvia officinalis L.) prepared at different temperatures", Applied Sciences, vol. 10, pp. 2270, 2020.

[8] K. Tenório, S. Sgavioli, B. Roriz, C. Ayala, W. dos Santos, P. Rodrigues, V. de Almeida, and R. Garacia. "Effect of Chamomile extract on the welfare of laying Japanese quail". Revista Brasileira de Zootecnia, vol. 46, no. 9, pp. 760-765, 2017.

[9] M. Moss, R. Jones, L. Moss, R. Cutter, and K. Wesnes. "Acute consumption of Peppermint and Chamomile teas produce contrasting effects on cognition and mood in healthy young adults", Plant Science Today, vol. 3, pp. 327-336, 2016.

[10] A. McDonnell and C. Dang, "Basic review of the Cytochrome P450 system", Journal of Advanced Practitioner Oncology, vol. 4, no.4, pp. 263-268, 2013.

[11] P. Manikandan and S. Nagini. "Cytochrome P450 structure, function, and clinical significance: A review" Current Drug Targets, vol. 19, no. 1, pp. 38-54, 2018.

[12] F. Guengerich, "A history of the role of cytochrome P450 enzymes in the toxicity of drugs", Toxicology Research, vol. 37, pp. 1-23, 2021.

[13] M. Stipp, and A. Acco, "Involment of cytochrome P450 enzymes in flammation and cancer: a review", Cancer Chemotherapy and Pharmacology, vol. 87, pp. 295-309, 2021.

[14] A. Paniagua and P. Amariles, "Hepatotoxicity by drugs, pharmacokinetics and adverse effects of drugsmechanism and risk factors", N. Malangu, IntechOpen, UK, 2017.

[15] E. Biömsson, "Hepatotoxicity by drugs: the most common implicated agents", International Journal of Molecular Sciences, vol. 17, no.2, pp. 224, 2016.

[16] S. Parish, M. Aschner, W. Casey, M. Corvaro, M. Embry, S. Fitzpatrick, D. Kidd, N. Kleinstreuer, B. Lima, R. Settivari, D. Wolf, D. Yamazaki, and A. Boobis, "An evaluation framework for new approach methodologies (NAMs) for human safety assessment". Regulatory Toxicology and Pharmacology, vol. 112, no. $104592,2020$.

[17] H. Heusinkveld, H. Braakhuis, R. Gommans, P. Botham, M. Corvaro, J. van der Laan, D. Lewis, F. Madia, I. Manou, F. Schorsch, G. Wolterink, R. Woutersen, R. Corvi, J. Mehta, M. Luijten, "Towards a Mechanismbased approach for the predication of nongenotoxic carcinogenic potential of agrochemicals", Critical Reviews in Toxicology, vol. 50, no. 9, pp. 725-739, 2020.

[18] C. Poussin, A. Iskandar, C. Mathis, D. Smart, F. Zanetti, M. van der Toorn, D. Bovard, R. Savioz, D. McHugh, W. Schlage, M. Peitsch, P. Vanscheeuwijck, J. Hoeng, "Toxicological assessment In Vitro", in Toxicological Evaluation of electronic nicotine delivery products, Chapter 13, M. Peitsch and J. Hoeng (Editors), Academic Press, ScienceDirect, USA, 2021.

[19] F. Pistollato, F. Madia, R. Corvi, S. Munn, E. Grignard, A. Painai, A. Worth, A. Bal-Price, P. Prieto, S. Casati, E. Berggren, S. Bopp, and V. Zuang, "Current EU regulatory requirements for the assessment of chemicals and cosmetic products: approach methodologies", Archives of Toxicology, vol. 95, pp. 1867-1897, 2021.

[20] O. Naodenko, D. Andrews, A. TEmkin, T. Stoiber, U. Uche, S. Evans, and S. Dray, "Investigating molecular mechanism of immunotoxicity and the utility of ToxCast for immunotoxicity screening of chemicals added to food", International Journal of Environmental Research Public Health, vol. 18, pp. 3332 (24 pages), 2021.

[21] H. Du, B. Pan, and T. Chen, "Evaluation of chemical mutagenicity using next generation sequencing: A review," Journal of Environmental Science and Health, Part C, vol. 35, no. 3, pp. 140-158, 2017.

[22] K. Rim and S. Kim, "A review of mutagenicity testing for hazard classification of chemicals at work: focusing on in vivo micronucleus test for allyl chloride," Safety and Health at Work, vol. 6, no. 3, pp. 184$191,2015$. 
[23] D. Sun, T. Zhao, T. Wang, M. Wu, and Z. Zhang, "Genotoxicity assessment of triclocarban by comet and micronucleus assay and Ames test" Environmental Science and Pollution Research International, vol. 27, no. 7, pp. 7430-7438, 2020.

[24] G. Srivastava, M. Alonso, I. Bueno, M. Gutierrez, F. Rull, J. Medina, R. Coco, and J. Pastor, "Comparison between direct contact and extract exposure methods for PFO cytotoxicity evaluation", Scientific Reports, vol. 8, pp. 1425, 2018.

[25] B. David, M. Jane, and C. Marco, "The natural cytotoxicity receptors in health and disease", Frontiers in Immunology, vol. 10, pp. 909, 2019.

[26] M. Azevedo, A. Portela, A. Romano, and M. Cenci, "Prevalence of teething symptoms in primary teeth and associated factors: cross -sectional study in children aged 12-23 months", Brazilian Research in. Pediatric Dentistry and Integrated Clinic, vol. 15, no. 1, pp. 217-225, 2015. 